\title{
LAY FORUMS IN CHILD WELFARE
}

\section{J Schmid}

\section{INTRODUCTION}

Dealing with child abuse presents many challenges to both policy makers and service providers internationally. Societies have responded differently to this issue (Gough, 1996). In Western countries two broad streams have emerged: one adversarial, the other consensual. The "child protection" approach, common in countries such as the UK, USA, Canada and Australia, has been criticised as being punitive and adversarial, typically marginalising the voice and experience of service users (Merkel-Holguin, 2004; Waldegrave, 2006; Waldfogel, 1998). A more collaborative approach to child welfare is captured in the "family services" and "community care" models, respectively typical of Europe and of aboriginal communities in "developed" countries. It should be noted that the limited literature on child welfare systems operating in "developing" countries implies that services mostly conform to a "child protection" approach as they tend to be residual, deficit based and treatment oriented, and are heavily skewed towards residential care options (Pilotti, 1999; Stockholm University, 2003; Xiaoyuan \& Xioaming, 2003). Indigenous helping approaches co-existing with these systems have typically been overlooked. The "community care" model hence constitutes the only child welfare model that formally articulates indigenous approaches.

In South Africa, a new Children's Act, No. 38 of 2005 (Republic of South Africa, 2006) has been introduced. In accordance with the recognition that the court system needs to become more child and family friendly (Loffell, 2003), the recent Act includes procedures such as mediation, family group conferencing and the use of traditional forums to engage with families in a non-adversarial way.

In this paper the author discusses the new Child Welfare Act and the corresponding measures to enhance engagement with families in abusive situations, using a critical, structural lens (Sewpaul, 2006). The intent of this article is not to promote practices originating in Western contexts as solutions for the South African scenario, or to replicate oppressive power dynamics regarding knowledge creation and ownership (Osei-Hwedie, 1995). Rather, bearing in mind that lay forums have now been written into the South African legislation, the goal is to explore what lessons can be learned about how various child welfare systems have made use of consensual, collaborative approaches, and how these can be considered in the South African context. It is hoped that this article will contribute to South Africans developing meaningful domestic approaches to child abuse through authentication (the re-discovery and re-generation of traditional helping means) and indigenisation (Mabetoa, 1999; Osei-Hwedie, 1995).

\section{SITUATING THE SOUTH AFRICAN CHILD WELFARE SYSTEM}

South Africa is a country that represents first world notions of development, while simultaneously dealing with extremes of underdevelopment, reflected in poverty, HIV/AIDS and violence. The South African child welfare system is overwhelmed by the demands being made on it (September, 2006). Appreciating the extent of vulnerability and abuse can be difficult as precise data are generally not available (September, 2006). However, it is known that extensive poverty and inadequate living conditions impact directly on South Africa's 19 million children, approximately $60 \%$ of whom are in dire need (Benjamin, 2005; Matthias, 2001; Samson et al., 2004). The lives of South African children have been transformed by the HIV/AIDS epidemic (Booysen \& Arntz, 
2002) with over 5\% of children infected (Patel, 2005) and around 1 million children having lost either one or both parents by 2005 (Padayachee, 2004; IRIN, 2005). There has been an unprecedented rate of violence against children and women in the last decade (Peacock \& Botha, 2005), Mkhize (2004) suggesting that children are dealing with "war zones" in their homes and communities where they experience physical abuse (Pierce \& Bozalek, 2004), sexual assault and exploitation (Kossie, 2005), are subject to child trafficking (Bower, 2004) and child labour, and deal with the fall out of domestic violence.

It is the author's contention that the orientation of the South African child welfare system makes it difficult for the sector to respond to the impact of HIV/AIDS, poverty and violence on vulnerable children and their families. The South African child welfare system, paralleling developments in welfare more broadly (Patel, 2005), was founded on colonial ideas (Allsopp, 2005), and shaped by apartheid philosophies and directives (Loffell, 1996). Furthermore, it was deeply influenced by "child protection" notions of child welfare, thus adopting an individualistic, remedial approach (Schmid, 2006). These ways of working are no longer effective in the current context. Attempts have been made on both a programmatic level (September, 2005; Sewpaul, 2001), and on a policy level - for example, The Interministerial Committee for Youth at Risk (Interministerial Committee, 1998), the National Policy Framework and Strategic Plan for the Prevention and Management of Child Abuse, Neglect and Exploitation (Department of Social Development, 2004) and the process around the Children's Bill and Act - to shift child welfare practices away from a predominantly therapeutic, case-based approach towards an approach that is more family centred, community based and service-user driven. As such, the new child welfare legislation, which is intended to deal with children who have been abused and neglected, departs from the Child Care Act No. 74 of 1983 on a number of levels. The definition of child abuse has been broadened from abuse (physical, sexual and emotional) and neglect to include exploitative labour practices, trafficking and corporal punishment as well as harmful traditional practices such as virginity testing and circumcision (Proudlock \& Jamieson, 2006). Both prevention and early intervention services are identified as important complements to statutory work. Residential facilities are required to provide more than custodial care and to offer therapeutic programmes. Changes aimed at increased effectiveness and efficiency of the children's court system are included (Child Welfare South Africa, 2005; Jamieson, 2005; Matthias, 1996; Proudlock, 2005). The voluntary sector argues that the legislation is not as radical as was originally intended as it does not reflect all their initial recommendations such as a robust social security system, the rights of certain categories of children and a commitment to total financing of non-governmental organisations by government (Children's Bill Working Group, 2003; Loffell, 2003; Proudlock, 2003). Thus child welfare remains a hotly contested area, lacking a comprehensive, clear vision that is consistent across both government and the non-governmental sector.

Furthermore, despite these attempts to overhaul the child welfare system, its essence remains child-protection focused. Thus, as Sewpaul (2005) argues of the Family Policy, the values and principles underlying local child welfare interventions reinforce notions that parents are solely responsible for meeting their children's needs (Sloth-Nielsen, 2005; Streak, 2004), thus justifying intrusive measures by the state (or proxies of the state) and reinforcing the role of "experts". While there is a greater emphasis on participation, "knowledges" carried by service users remain largely marginalised, as professional discourses continue to be asserted. Systemic issues and their impact on family capacity tend to be overlooked, as prevention and early intervention measures are directed primarily towards parental functioning, disregarding the importance of dealing with structural issues and strengthening family and community networks (Schmid, 2006). 
The focus of this paper is on the provisions in the Children's Act (2005) for the use of intermediary structures in the form of mediation (which has long been used in the family court), family group conferencing and traditional forums. Specifically, the recommendations include the following:

- Clause 33 (4) (b) notes that, in preparing a parenting plan, the parties must seek the assistance of a family advocate, social worker or psychologist, or alternatively mediation through a social worker or other appropriate person;

- Clause 49 suggests that lay forum hearings may include mediation by a family advocate, social worker, social service professional or other professionally qualified person; a family group conference; or mediation as in section 71. Before ordering a lay forum hearing the court must take into account all relevant factors, including the vulnerability of the child, the ability of the child to participate in the proceedings, the power relationships within the family, and the nature of any allegations made by parties in the matter;

- Clause 70 notes that the children's court may request a family group conference in order to find solutions for any problem involving the child. The court must appoint a suitably qualified person or organisation to facilitate the process; prescribe the manner in which a record is kept of any agreement or settlement reached between the parties, and any fact emerging from such conference which ought to be brought to the notice of the court; and consider the report on the conference when the matter is heard;

- Clause 71 identifies that the children's court may refer a matter to any appropriate lay forum, including a traditional authority, in an attempt to settle the matter by way of mediation out of court. Lay forums may not be held in the event of a matter involving the alleged abuse or sexual abuse of a child.

It should be noted that the writer is working on the assumption that Family Group Conferencing referred to in the legislation constitutes the child welfare application rather than the restorative justice application, which is the subject of the Child Justice Bill No. 49 of 2002, though both applications might be useful in dealing with families involved with the child welfare system.

These inclusions regarding lay forums are critical and signal a shift in working with families by promoting their participation in decision-making processes that affect them. More importantly, they are culturally appropriate given that lekgotlas and indabas have long been used in African cultures and are traditional ways of decision making and resolving conflicts, which are thus familiar to African clients. Collaborative approaches also reinforce the collective spirit of Ubuntu, which has been historically significant.

However, lay forums as described in the new legislation will be hindered as significant alternatives to court procedures or in contributing meaningfully to a less adversarial, more consensus-based child welfare system, because the court remains the primary forum for formal decision making and retains its adversarial character. The legislation also reinforces a residual approach in allowing magistrates to order early intervention programmes. It thus is useful to explore how lay forums have been used in other contexts and what lessons may be learnt by South Africans from these experiences to ensure that lay forums do result in better outcomes for service users.

\section{MODELS OF CHILD WELFARE IN "FIRST WORLD” COUNTRIES}

Internationally, child welfare approaches differ depending on prevailing cultural ideas about how the state should intervene with families, attitudes to parenting and childrearing, and beliefs about 
child maltreatment (Freymond \& Cameron, 2006; Hill, Stafford \& Lister, 2002). Freymond and Cameron (2006) identified three policy models in the "First World", each offering fundamentally different ways of constructing child welfare, namely, the "family services" model used in Europe; the "community care" model articulated by the Aboriginal and First Nations Peoples in developed Western countries; and the "child protection" model used in North America, the UK and Australia. These models offer only a typology for child welfare systems, with all countries having unique approaches that reflect their particular context (Freymond \& Cameron, 2006). As the following discussion shows, the "family services" and "community care" models focus on supporting families with their childrearing activities and regard child safety as a joint responsibility of the family and the state. For the most part, "family-friendly" approaches are used. The "child protection" model focuses on safety, is increasingly risk directed, and tends to be seen as adversarial.

\section{Family Services: the European model}

In Western Europe - typified by social democratic and corporatist welfare states (EspingAnderssen, 1990) - child welfare systems generally follow a "family services" model (Freymond \& Cameron, 2006) where solidarity and social inclusion are valued and the child welfare function is embedded within a broader spectrum of social services (Waldegrave, 2006). The interaction between families and child welfare systems tends to be non-confrontational and focused on finding joint solutions. Social workers engage cooperatively with families to address their needs (Freymond \& Cameron, 2006). The court's role is to investigate abuse and negotiate consensusbased agreements with families wherever possible (Freymond, 2001; Hill et al., 2002). In France, for example, judges are trained in child welfare and are supported by a corps of social workers, rather than legal personnel (Waldegrave, 2006). In the juge des enfants approach, parties (families) tend not to have legal representation (Freymond, 2001), even where the parents are mandated to attend against their will (as when they are suspected of child abuse). French judges also advise on child welfare matters relatively early in proceedings compared to other legal systems (Bilson \& White, 2005). Furthermore, children are entitled to request a hearing (Bilson \& White, 2005).

Mandatory reporting, a core feature of the "child protection" model, is not consistently required across continental Europe. For example, in Belgium and the Netherlands, the "Confidential Doctor" system allows families to discuss concerns with a doctor without risking judicial involvement (Freymond, 2001; Hill et al., 2002). Children may self-refer and confidentiality is maintained as long as this is what the child chooses (Hill et al., 2002). Families in trouble are thus able to access services in a non-threatening manner. In such systems families frequently seek help and become engaged with professionals on a voluntary basis, rather than being coerced to do so (Freymond, 2001).

Mediation is also used in many European countries (Hill et al., 2002). For example, in Belgium it involves a six-member panel of community volunteers who are trained both as mediators and in child welfare matters. Only where agreement between the parties cannot be reached does the case proceed to a court hearing (Freymond, 2001).

In recent years countries such as the Netherlands, Sweden and Norway have introduced Family Group Conferencing (FGC) (Pagee, 2004; STAKES, n.d; Sundell \& Vinnerljung, 2004), as described under New Zealand's Children, Young Persons and their Families Act 1989, utilising both the child welfare and the restorative justice approaches. This approach will be expanded on below as it forms the basis of one kind of "community care" model. 


\section{Community care: The indigenous model}

The "community care" model is used by many indigenous peoples in Canada, the United States (Freymond \& Cameron, 2006; Hill, n.d), Australia (Ban, 2005) and New Zealand (Connolly, 1999). Indigenous peoples value collectivism, communitarianism, connectivity, inclusion, consensus and interdependence (Freymond \& Cameron, 2006). Here the emphasis is on keeping children within their own cultures, where community is family and kin extends beyond the confines of the immediate family. The involvement of the child's family network in child welfare decision-making processes is vital and the wisdom, expertise and knowledge of kith and kin are highly valued (Love, 2000).

Indigenous child welfare systems exist alongside the mainstream child-protection system in these contexts with varying degrees of autonomy (Love, 2006). Family Group Conferencing (FGC) is an example of a mainstreamed "community care" model, and is based on Maori culture and traditions. Two different family group conferencing approaches are described in the original Act in New Zealand, though both are premised on the same values. In the restorative justice approach, young people in trouble with the law are brought together with the subject of, and those affected by, the wrongdoing. In the child welfare approach, applied in situations where children are considered to be at risk, the family group (including immediate family, relatives and significant others), and service providers are brought together to develop plans for the child's safety and wellbeing (Connolly, 1999). The intent of the latter conferencing forum is to make decisions rather than to resolve conflict, although differences may be dealt with in the process of developing a jointly approved plan. The child welfare family group conference usually begins with a culturally appropriate opening chosen by the family and with service providers sharing pertinent information. The family group meets in a private caucus to develop recommendations. These proposals are then reviewed by service providers, and are accepted if there is agreement that the child's needs for safety and well-being will be met through the plan (Burford \& Hudson, 2000). Good preparation is critical and the process is time-consuming, taking around 30 hours.

Indigenous approaches cannot be simply translated from one aboriginal context to another. In Canada, for example, while some native ${ }^{1}$ Canadians have found conferencing useful, many First Nations People have rejected family group conferencing because they would rather employ their own cultural practices, which allow for inclusive and restorative resolutions, but which have historically been ignored and devalued (Tauri, 1999).

\section{Child protection: The Anglo-American model}

In the United Kingdom, Australia, the United States and Canada (where governments can be characterised as liberal or neo-liberal), "child protection" is the dominant model of child welfare (Freymond \& Cameron, 2006). The "child protection" model is individualistic, remedial and sees parents as primarily responsible for their children's welfare (Freymond \& Cameron, 2006; Waldegrave, 2006). It tends to be intrusive, punitive, confrontational and adversarial (Waldfogel, 1998), though in recent years attempts have been made to work more cooperatively with families. For example, "intermediary structures", such as mediation and family group conferencing, have been established to "...circumvent the involvement of the law in a coercive manner" (Freymond, 2001:7). There has been growing interest in family group conferencing in North America, England and Australia following its introduction in New Zealand in 1989 (AHA website, n.d). In Canada and America mediation has been used in relation to familial neglect and abuse. Despite its limited

\footnotetext{
${ }^{1}$ It should be noted that the term "native Canadian" is the appropriate term for indigenous or First Nations Canadians.
} 
application, positive outcomes have been reported, such as high completion rates and reduced court costs (Landsman, Thompson \& Barber, 2003; Maresca, 1995). Generally, the mediation is managed by a trained professional. The nature of the intervention can vary. Landsman et al. (2003) mention two applications, one in Toronto, where the parties are prepared individually and then meet together for a joint session in which the conflict is addressed, and another in Iowa, where multiple sessions are held over a longer period of time.

The purpose of these models is to engage family members in the child-protection system. Another method used is "wraparound" (Vandenberg \& Grealish, 1996), where child welfare clients, such as parents who wish to be re-united with their children or teenagers experiencing conflict with their parents, choose a team to enable them to develop and implement a strategy to address the issue. The team (typically about 5-8 members) is comprised of relatives, friends and service providers. A facilitator supports the team in identifying clear objectives and steps towards realising them. Successive meetings are held until the goals are met. The wraparound process, while espousing similar principles to Family Group Conferencing, is driven by the service user rather than by the family group as a whole.

Intermediary spaces have also been created in other ways. In Scotland, for example, if there is agreement regarding the facts of the case, the matter can be heard by a panel of three lay volunteers instead of requiring a formal court hearing (Freymond, 2001). The Scottish also use social workers in place of lawyers to represent children's best interests (Bilson \& White, 2005), in the belief that this will make the process less adversarial. In the United States "citizen volunteers" are used in many states to advise the courts regarding the child's best interests (Bilson \& White, 2005). This writer is concerned that these latter approaches, in attempting to ensure that the interests of all parties are represented appropriately at court, may result in both over-representation and over-professionalisation. As such, ironically, the authentic voice and lived experience of service users being represented are potentially lost as their views are translated by a range of "experts" into professional jargon. Secondly, in focusing on individual needs, it is possible that collective interests and concerns may be overlooked. Thirdly, this dynamic leads to an increasingly adversarial environment, where common ground and joint agreements are difficult to find. Thus, rather than an intermediary space, another level of bureaucracy is created. The challenge is therefore to find ways of strengthening the respective parties' voices, while ensuring that no-one is being silenced and that each person's rights are acknowledged. Mediation and family group conferencing are useful approaches as they allow all parties involved to speak for themselves, to be heard and to participate in developing solutions. More importantly, their strengths and competence are affirmed in the process (Burford \& Hudson, 2000; Landsman et al., 2003).

Lay forums can offer a creative means to make the statutory child welfare and associated judicial system more accountable and accessible to service users, and to promote a consensus-based, partnership approach to decision making in child welfare cases. In a "child protection" context inclusive approaches tend to be resisted or diluted, as they ultimately challenge the hierarchy on which the system is based. Thus, maintaining model integrity is critical if the intended benefits for service users are to be realised (Schmid \& Sykes, 2006).

\section{LAY FORUMS IN THE SOUTH AFRICAN CHILDREN'S ACT}

It is important to consider the provisions of the Children's Act and to appreciate the extent to which these lay the ground for increased collaboration within, and democratisation of, child welfare processes in South Africa. These proposals are also significant in that they formally affirm the previously marginalised "knowledges" surrounding indigenous practices and values. 
While it is positive that the legislation makes room for lay forums, some restrictive inclusions in the Act threaten to undermine their effectiveness. First, in terms of the Act, the "best interests of the child" forms the central premise for decision making. Burman (2003) cautions that the manner in which best interests are understood may promote an individualised view and thus pit families' interests against those of the child, rather than appreciating the way these are intertwined in many cultures. This is an important issue, particularly when utilising traditional forums, where notions of collectivity and interdependence are fundamental.

The fact that mediation and family group conferencing must be ordered by the court may be a second impediment as these processes rely on the voluntary participation of clients and might not be effective when statutorily enforced. The intent is to allow service users a voice in the decisionmaking processes that affect them. These processes offer a means of democratising child welfare because of their strengths-based focus drawing on the expertise of the family group (MerkelHolguin, 2004). Mediation is most often used in conflict situations where those involved have reached an impasse, but it requires clients to participate willingly. It is harder to find creative solutions and meaningful compromise when participants feel coerced and it is also less likely that agreement will be implemented in such circumstances. In the case of family group conferencing, caregivers can be ordered to participate, but it is untenable to think that relatives or friends should be compelled to do so. In New Zealand conferencing is mandatory (Connolly, 1999). Rather than being ordered, this means that in every case where there is a child-protection concern, a conference coordinator invites family members to attend and the conference proceeds regardless of whether they choose to participate. Thus Judge Hoover (2005:2) says, "Keep the process voluntary. When judges order FGDM (family group decision making), it gives ownership to the bench, not the family." Hence, ordering family members into a mediation or family group conferencing process is inappropriate, though a magistrate can order the parties to consider participation in such processes. The magistrate, however, must also make it clear that no penalty will ensue should the parties decide not to proceed, or should the mediator or coordinator assess that the process would be inappropriate in the particular situation. Ideally, family members should be routinely invited by child welfare workers to participate in mediation and conferencing forums rather than this being left to the court. If agreement cannot be reached, the matter can at that point be referred to court.

A further concern is that the Act directs that a magistrate must consider the power dynamics in a family before ordering participation in these processes. Certainly mediators and conference coordinators need to assess whether or not referrals are appropriate. For example, mediation is seldom used in domestic violence situations. Mediation can indeed lead to secondary victimisation (both for the women who were abused and for children in the family) where mediators are insufficiently attuned to the issues within domestic violence situations (Johnson, Sacuzzo \& Koen, 2005). However, there are situations where, with a skilled mediator who is familiar with the dynamics of spousal abuse, mediation can be appropriate. Family group conferencing is used in instances of domestic violence typically only when the perpetrator has admitted the abuse. The conference coordinator ensures that plans which ensure the emotional and physical safety of participants are set up prior to the conference (Pennell \& Burford, 2000). There is a range of strategies that the coordinator employs in conjunction with the family group to facilitate a safe space for discussion and planning. These include: (i) encouraging anyone who feels vulnerable to bring a friend or relative as a support person; (ii) widening the circle so as to ensure that a variety of perspectives are represented in the room, and to dilute the intensity of tensions that may exists in subgroups within the family; (iii) having very pointed discussions with any member of the family group who is identified as potentially threatening as to how they are perceived, and identifying with them what they require to act safely in the conference; (iv) excluding the physical 
presence of family members if this is absolutely required; and (iv) honouring any court orders that prevent contact between particular individuals, though variations are applied for where this appears appropriate to family group members (Family Group Conferencing Project of Toronto, 2006). Putting a safety plan in place allows a family group to be able to meet in a constructive and effective fashion when they might otherwise not have been able to do so.

Thus, while caution is most certainly required where there is abuse, leaving the responsibility for assessing the power dynamics among prospective participants to the magistrate may not be useful. This is partly because the court may not refer a family where there is violence when, in fact, with appropriate preparation, this family could indeed have had a worthwhile conference. Further, the mediators or conference coordinators are in a better position to assess whether family members can participate in a process effectively. Coordinators in particular meet with a wide representation of the family group, whereas the magistrate will generally only have met members of the nuclear family.

Similarly, coordinators or mediators should make the assessment as to whether children participate in the forum or conference (Holland \& O’Neill, 2006). Increasingly, children are recognised as having agency and thus the child's perspectives need to be heard. How the child's voice will be represented is negotiated by the facilitator with the child, the family circle and, where appropriate, the referring social worker. In the Toronto conferencing project, children of all ages attend the conference, though they and the adults will decide how much of the time the child spends in the meeting or in the playroom (Family Group Conferencing Project of Toronto, 2006). The same principles for safety, as were identified earlier, are followed to ensure that children feel secure when participating directly in the conference.

Another restriction placed on lay forums in the Act is that they cannot be used in situations of physical and sexual abuse. It is not clear if this applies to conferencing as well. Family group conferencing has been used internationally in all child-protection matters, including neglect, and emotional, physical and sexual abuse (Helland, 2005). In the applications for mediation and conferencing with which the writer is familiar, parties need to accept certain conditions to enter the process. In family group conferencing, the child welfare workers involved identify "bottom lines" or "non-negotiables", which are essentially the parameters within which the family group must work (Family Group Conferencing Project of Toronto, 2006). For example, a bottom line might be that a mother will not be considered as a primary caregiver because of her long history of substance abuse. Although exclusion is a last resort, decisions are sometimes made not to have everyone present at the conference. Absent parties can be represented by other members of the family circle, can present their views through letters or, if appropriate, participate by phone (Merkel-Holguin \& Wilmot, 2004). Mediation similarly can also be used in situations of abuse. In the Toronto model of child abuse mediation in which the writer has participated, a referral to discuss whether or not abuse has occurred is not accepted. In other words, parties have to agree that there has been abuse before entering mediation. Mediation thus offers a non-adversarial manner of dealing with such issues as custody and access, developing plans for permanency and/or re-unification (Landsman et al., 2003), and resolving conflicts between workers and family members. In summary, the procedures themselves incorporate the necessary safeguards to be able to deal with a broad range of child welfare concerns.

Deciding which strategy to use with a particular family group will depend on the nature of the issue the family is dealing with, as well as their particular culture and preferences, as not all approaches may be suitable for a particular family. The principle is to ensure that family networks have a voice in the decisions that affect them. 
Finally, Clause 70 also gives cause for concern as it implies that the court has influence over the role of the coordinator in the process. It states that:

"The court must appoint a suitably qualified person or organization to facilitate; prescribe the manner in which a record is kept of any agreement or settlement reached between the parties and any fact emerging from such conference which ought to be brought to the notice of the court; and consider the report on the conference when the matter is heard." (Children's Act, 2005, clause 70)

The writer is opposed to this and believes that record keeping and submissions should not be subject to an individual magistrate's opinion and rather needs to be standard across all cases. In family group conferencing only the names of participants and the plan that has been agreed upon by the family network and child welfare representatives are divulged to the court. The rest of the process remains private, though, depending on local legislation, coordinators may be responsible for informing authorities if they learn that a child might be placed at risk. Similarly in the Toronto mediation model, only the agreement is shared with the court. In each instance the coordinator or mediator does not attend court hearings. The agreements are brought to the court by the child welfare authorities. Restricting reporting allows the coordinator or mediator to maintain an independent position between the family network and the child welfare system, which is critical to the successful facilitation of the conference (Merkel-Holguin \& Wilmot, 2004). Furthermore, neither the coordinator nor the mediator is in a position to effectively assess parenting/care-giving capacity and to make meaningful recommendations. Expecting these professionals to take on such a role is not feasible and would place them in a potentially adversarial position vis-à-vis the family group, and undermines the role of the child welfare worker.

As regards the independence of coordinators and mediators, while it is appropriate that the court identify suitably qualified and accredited individuals or agencies to manage the conferencing or mediation process, individual facilitators themselves should not be "court-appointed" as this places them in a position of "statutory authority". Research by Johnson et al. (2005) suggests that where mediators are court appointed, mediation participants will take the lead from mediators' recommendations, or will attempt to offer plans that are deemed appropriate by the mediator because of the authority associated with the position. It needs to be emphasised that mediators and coordinators can only enable participants to come to meaningful decisions where the facilitator does not develop a vested interest in the plan (Merkel-Holguin \& Wilmot, 2004). In the case of traditional or religious forums, there needs to be societal consensus on whether these arenas are harmful or helpful (Waldegrave, Tamasase, Tuhaka \& Campbell, 2003) rather than the decision resting with an individual magistrate.

\section{FURTHER CONSIDERATIONS}

Two sets of issues which are not directly covered under the Act also need to be considered when utilising lay forums in planning and conflict resolution in child welfare. The first has to do with the rationale for using lay forums. The other has to do with the practicality of implementing such options in the South African context.

Lay forums are processes that facilitate partnerships between service providers and service users. While the Act does imply that lay forums are to be used to promote the facilitation of consensusbased decision making and to provide alternatives to the formal court process, consideration is not explicitly given to the need for democratising child welfare processes and how this can be achieved. The White Paper (Department of Welfare, 1997) stresses that developmental social welfare approaches require a participatory element that allows service users to be involved in 
decisions that directly affect them. As such, professionals have to appreciate that power needs to be shared with families, thus challenging their role as "expert". Against this background, lay forums need to become one mechanism within a broader toolbox of interventions that valorises the family's voice, expertise and context. Thus, approaches which affirm the larger family network as well as the unique culture of the family circle should be used as early as possible. Expanding the family network, in line with the expanded definition of family in the Children's Act, acknowledges the broader cultural network of the extended family system within local cultures (Burman, 2003). Inviting the family group into child welfare interventions, such as family preservation programmes, allows for a strengthening of the family circle around the child. This is critical for two primary reasons. First, households are often fluid, with children moving between homes and relatives (Booysen \& Arntz, 2002; Meintjies, Budlender, Giese \& Johnson, 2003). Thus the focus should not be only on existing caregivers, but on everyone connected to the child. Furthermore, knowing that informal support systems are under threat and stretched to the maximum in the light of social problems such as unemployment and HIV/AIDS (Booysen \& Arntz, 2002), it is important to preserve and extend these family support systems as much as possible. Wraparound and family group conferencing allow the promotion of collaborative relationships between child welfare workers and family members, reinforce connections between family members, affirm children's sense of belonging with "their people", and ensure that robust plans are implemented towards ensuring the child's safety and well-being. The prevention and early intervention programmes recommended in the Act need to be universal and non-stigmatising, thus reaching community members before they become identified with a particular problem and facilitating positive relationships with families.

A second issue is that of the feasibility of the use of lay forums in the South African context. Two primary questions need to be addressed: is this a resource-intensive process that will privilege only certain families, and are these approaches more suitable for certain families or individuals? The issue of resources is critical as these strategies will not be successful without stable and secure funding (Landsman et al., 2003). Unfortunately the Act does not speak to how these processes will be supported. This is a major consideration in a landscape where welfare services are severely under-resourced. There are indeed numerous immediate expenses involved, among them the cost of coordinators or mediators, a neutral venue, travel (both local and, in some cases, long distance), food, childcare and translation (Family Group Conferencing Project of Toronto, 2006). Given that South African families typically are spread over urban and rural areas, travel and potentially also accommodation costs are a significant outlay. However, while these approaches are expensive in the short term, it can be argued that the typical child-protection interventions with families are extremely costly and that individualised, isolated, adversarial approaches also tend not to be effective in curbing child abuse (Freymond \& Cameron, 2006; Patel, 2005; Waldfogel, 1998). Furthermore, the costs are worthwhile if the process is likely to take the case out of the court and child welfare system, thus avoiding long-term expenditures. While costs are a major concern, these alternative strategies should be introduced not only because they are more effective overall and efficient in the long term, but also because they offer the service user a voice in the decisionmaking process.

In terms of which families are better served by lay forums, the assumption might be made that these interventions are more appropriate for rural families (where family networks and traditional practices are assumed to be stronger) than for urban families. However, the reality is that most family groups have both urban and rural bases. The challenge becomes reaching family members to be able to invite them into the process, and there is no doubt that this will present difficulties in the South African context, bearing in mind uneven communication systems, safety issues and distance. Primarily, it may mean that it will take longer to set up conferences as arrangements will 
have to be made to contact various kith and kin. In some cases family members will need to be represented by other relatives, or by letter. Relatives from afar can also participate by phone. Finding a circle for persons who appear isolated (such as street children or new immigrants) can be a challenge. Coordinators attempt as far as is feasible to track down relatives using national data bases where appropriate, placing newspaper adverts or working by word of mouth. Persons who have become alienated from their immediate family may still be able to identify peers and potentially members of the extended family system who can be invited into a conference. There may be others in the community with whom they have forged a bond. All these individuals may become the channel through which a connection to parents or siblings is made. New immigrants may have developed links with others of similar backgrounds. The role of facilitator does require persistence, particularly in the conferencing context where the assumption is that larger numbers of people are needed for a successful outcome.

Another issue that merits consideration is who should be the facilitators of lay forums such as family group conferences, wraparound processes and mediation. This has been dealt with in various ways internationally. In places such as Sweden and the United Kingdom, conference coordinators may be lay persons who have "people skills". In the Toronto FGC project, a human services background is required (Family Group Conferencing Project of Toronto, 2006). In the United States these roles are typically taken by qualified social workers. It is the writer's view that these roles do not have to be over-professionalised and that the principles and values carried by the facilitator are key: the facilitator must credit the knowledge and experience of family members and needs to understand the inherent power dynamics that occur between child welfare professionals and service users (Holland, Scourfield, O’Neill \& Pithouse, 2005), and within families. Facilitators do need to develop an understanding of the child welfare system and have an appreciation of group dynamics. Bearing in mind the shortage of social workers in South Africa (Briede \& Loffell, 2004), it is worth considering training a corps of lay personnel as facilitators for these processes.

\section{CONCLUSION}

In this paper the writer argues that lay forums, which have been successfully used in several developed Western contexts and have been included in recent South African legislation, can make an important contribution to child welfare in South Africa, since they create the opportunity for service users to have a voice in decision-making processes that impact on their own and their children's lives. They permit participants to arrive at plans that are meaningful to them, and thus are more likely to be implemented. Such plans usually result in improved outcomes for children. They facilitate the inclusion of the service user's expertise on their family in the planning or conflict-resolution process. They allow for service users and service providers to develop partnerships, rather than work at odds with each other, and strengthen family support systems. Most importantly, they can be culturally appropriate and build on traditional and informal means of helping. Finally, they enable consensus-based decision making, thus reducing the number of cases that need to go before a magistrate, and decreasing the time that these cases are before the court.

However, to enable lay forums to be effective, service users should be invited to participate in these processes as early as possible in their involvement with child welfare. Participation needs to be voluntary. Ideally, family group conferencing and mediation should be offered before court procedures are instituted. The invitation should preferably come from child welfare workers rather than being ordered by a magistrate. The guiding principle for these consensus-based approaches should be to develop collaborative relationships with family members, rather than only focusing on the end phase of the child welfare process, which is the courts. If it is believed that such 
strategies provide meaningful, relevant alternatives to "child protection" practices, they will also have to be resourced.

\section{REFERENCES}

ALLSOPP, M. 2005. Tracing our history: Contextualising child and youth care within a South African reality, Part I. Child and Youth Care, 23(7):22-27.

AHA (AMERICAN HUMANE ASSOCIATION). FAMILY GROUP CONFERENCING WEBSITE. 2006. Available: www.fgdm.org [Retrieved on 30 June, 2006].

BAN, P. 2005. Aboriginal child placement and Family Group Conferences. Australian Social Work, 58(4):384-394.

BENJAMIN, J. 2005. Inauguration ceremony of the first professional boards of for social work and child and youth care. Child and Youth Care, 23(4):9-10.

BILSON, A. \& WHITE, S. 2005. Representing children's views and best interests in court: an international comparison. Child Abuse Review, 14:220-239.

BOOYSEN, F. \& ARNTZ, T. 2002. Children of the storm: HIV/AIDS and children in South Africa. Social Dynamics, 28(1):170-192.

BRIEDE, M. \& LOFFELL, J. 2005. Making social work workable. Children First, 61(May/June). Available: www.childrenfirst.org.za [Retrieved 9 July, 2005].

BURFORD, G. \& HUDSON, J. (eds) 2000. Family group conferencing: New directions in community-centered child and family practice. New York: Aldine de Gruyter.

BURMAN, S. 2003. The best interests of the South African child. International Journal of Law, Policy and Family, 17:28-40.

CHILDREN'S BILL WORKING GROUP. 2003. The Children's Bill has lost its soul. Unpublished paper.

CHILD WELFARE SOUTH AFRICA 2005. South African Council for Child and Family Welfare: Triennial report, 2002-2004. Unpublished document.

CONNOLLY, M. 1999. Effective participatory practice: Family Group Conferencing in child protection. New York: Aldine de Gruyter.

DEPARTMENT OF WELFARE (DW). 1997. White Paper for Social Welfare. Available: www.socdev.gov.za [Retrieved: 10 August, 2005].

ESPING-ANDERSEN, G. 1990. The three worlds of welfare capitalism. Cambridge: Polity Press. Available: http://www.ucc.ie/social_policy/Esping-Andersen.htm [Retrieved: 20 January, 2006].

FAMILY GROUP CONFERENCING PROJECT OF TORONTO (FGCPT). 2006. Manual for coordinators. Author.

FREYMOND, N. 2001. Using intermediary structures to support families: An international comparison of practice in child protection. Monograph. Kitchener-Waterloo: Wilfrid Laurier University, Department of Social Work. 
FREYMOND, N. \& CAMERON, G. 2006. Towards positive systems of child and family welfare: International comparisons of child protection, family service and community caring systems. Toronto: University of Toronto Press.

GOUGH, D. 1996. Defining the problem. Child Abuse and Neglect, 20(11):993-1002.

HELLAND, J. 2005. Family group conferencing literature review. International Institute for Child Rights and Development, UVIC.

HILL, L. [n.d.] Family group conferencing: An alternative approach to the placement of Alaska native children under the Indian Child Welfare Act. Available: www.law.duke.edu/journals/alr/articles/alr22p89.htm [Retrieved June 26, 2006].

HILL, M., STAFFORD, A. \& LISTER, P. 2002. International perspectives on child protection. Available: $\quad$ www.scotland.gov.uk/Topics/Peoople/Young-People/children-families/17834/10633 [Retrieved: June 1, 2006].

HOLLAND, S. \& O’NEILL, S. 2006. "We had to be there to make sure it was what we wanted": Enabling children's participation in family group decision-making through the family group conference. Childhood, 13(1):91-111.

HOLLAND, S., SCOURFIELD, J., O’NEILL, S. \& PITHOUSE, A. 2005. Democratising the family and the state? The case of family group conferences in child welfare. Journal of Social Policy, 34(1):59-77.

HOOVER, T. 2005. The critical role of leadership in implementing Family Group Decision Making. American Humane FGDM Issues in Brief.

INTERMINISTERIAL COMMITTEE ON YOUNG PEOPLE AT RISK. 1998. Minimum standards: South African child and youth care system. Draft. Author.

IRIN. 2005. South Africa: New action plan to assist OVC underway. Available: www.irinnews.org [Retrieved: 1 August, 2005].

JAMIESON, L. 2005. Vote is a milestone for defence rights. Children First, 62(July/August). Available: www.childrenfirst.org.za [Retrieved: 25 November, 2005].

JOHNSON, N., SACUZZO, D. \& KOEN, W. 2005. Child custody mediation in cases of domestic violence: Empirical evidence of a failure to protect. Violence Against Women, 11(8):1022-1053.

KOSSIE, N. 2005. Campaign against child trafficking. Children First, 63 (September/October). Available: www.childrenfirst.org.za [Retrieved: 25 November, 2005].

LANDSMAN, M., THOMPSON, K. \& BARBER, G. 2003. Using mediation to achieve permanency for children and families. Families in Society, 84(2):229-239.

LOFFELL, J. 1996. Social work intervention in child sexual abuse. Johannesburg: University of Witwatersrand. (Doctoral dissertation)

LOFFELL, J. 2003. Children in need of care. Supplement to Dawes, A (Ed.). The state of children in Gauteng. A report for the office of the premier, Gauteng provincial government. Pretoria: Child youth and family development, Human Sciences Research Council. Unpublished manuscript.

LOFFELL, J. 2003b. Rights with no resources. Children First, 50(August/September). Available: www.childrenfirst.org.za [Retrieved: 20 January, 2005]. 
LOVE, C. 2000. Family group conferencing: Cultural origins, sharing, and appropriation- a Maori reflection. In: BURFORD, G. \& HUDSON, J. Family group conferencing: New Directions in community-centred child and family practice. New York: Aldine de Gruyter: 15-30.

LOVE, C. 2006. Maori perspectives on collaboration and colonization in contemporary Aoterearoa/New Zealand and family welfare policies and practices. In: FREYMOND, N. \& CAMERON, G. (eds) Towards positive systems of child and family welfare: International comparisons of child protection, family service and community caring systems. Toronto: University of Toronto Press: 237-268.

MABETOA, M. 1999. Indigenization of a school social work model for rural communities in South Africa. Social Work/Maatskaplike Werk, 35(1):39-48.

MARESCA, J. 1995. Mediating child protection cases. Child Welfare, (Special Issue, June): 731 742 .

MATTHIAS, C. 1996. Are we making progress? The 1996 Child Care Bill and some fundamental aspects of practice and procedure in Children's courts. Social Work/Maatskaplike Werk, 32(3):242-247.

MATTHIAS, C. 2001. Promoting proactive services and an inter-sectoral approach on behalf of children: an important new South African initiative. International Social Work, 48(6):753-762.

MEINTJIES, H., BUDLENDER, D., GIESE, S. \& JOHNSON, L. 2003. Children in "need of care" or in need of cash? Questioning social security provisions for orphans in the context of the South African AIDS epidemic. Available: www.web.uct.ac.za/depts/ci [Retrieved: February 14, 2006].

MERKEL-HOLGUIN, L. 2004. Sharing power with the people: Family Group Conferencing as a democratic experiment. Journal of Sociology and Social Welfare, 31(1):155-173.

MERKEL-HOLGUIN, L. \& WILMOT, L. 2004. Family group conferencing: Responses to the most commonly asked questions. National Centre on Family Group Decision Making, American Humane Association.

MINISTER OF SOCIAL DEVELOPMENT. CHILDREN'S BILL 2003. B70-2003 (Reintroduced). South African Government Gazette No. 25346 of August 13, 2003. Government Printer.

MKHIZE, N. 2004. Society's war against children: daily crimes against humanity go unpunished. Children First, 57, September/October. Available: www.childrenfirst.org.za [Retrieved: 5 October, 2005].

NATIONAL RESEARCH AND DEVELOPMENT CENTRE FOR WELFARE AND HEALTH (STAKES). (n.d). Family Group Conferencing in the Nordic Countries. Available: http://www2.stakes.fi/hyvinvointi/NFRS/english/english.htm [Retrieved: June 30, 2006].

OSEI-HWEDIE, K. 1995. A search for legitimate social development education and practice models for Africa. Studies in African Economic and Social development, Volume 7. Lewiston: The Edwin Mellen Press.

PADAYACHEE, S. 2004. Pooling resources to address needs. Children First, 54 (March/April). Available: www.childrenfirst.org.za [Retrieved: 20 January, 2005]. 
PAGEE, R. 2004. Conferencing in the mainstream. Paper presented at the third conference of the European Forum for Victim-Offender Mediation and Restorative Justice. "Restorative Justice in Europe: Where are we heading?" Budapest, Hungary. 14-16 October, 2004. Available: www.euforum.org/readingroom/Budapest/workshop3.pdf [Retrieved: June, 30, 2006].

PATEL, L. (ed) 2005. Social welfare and social development in South Africa. South Africa: Oxford University Press.

PEACOCK, D. \& BOTHA, M. 2004. Sharing responsible models of fatherhood. Children First, 57(September/October). Available: www.childrenfirst.org.za [Retrieved: 20 January, 2005].

PENNELL, J., \& BURFORD, G. 2000. Family group decision making and family violence. In: BURFORD, G. \& HUDSON, J. (eds) Family Group Conferences: New directions in community-centered child and family practice. New York: Aldine de Gruyter: 253-261.

PILOTTI, F. 1999. The historical development of child welfare systems in Latin America- an overview. Childhood, 6(4):408-422.

PROUDLOCK, P. 2003. Will 2003 be the year of delivery for children? Child and Youth Care, 21(3):11-13.

PROUDLOCK, P. 2005b. Another paper list or a means of protection? Children First, 59(January/February). Available: www.childrenfirst.org.za [Retrieved: 7 July, 2005].

REPUBLIC OF SOUTH AFRICA 2006. Children's Act, No. 38 of 2005. Government Gazette, Vol. 592, 19 June, 2006. Available: www.info.gov.za/gazette/acts/2005/a38-05 [Retrieved: 6 October, 2006].

SAMSON, M. et al. 2004. The social, economic, and fiscal impact of a basic income grant for South Africa. In: STANDING, G. \& SAMPSON, M. (eds) A basic income grant for South Africa. Cape Town: UCT Press.

SCHMID, J. 2006. Towards a responsive South African child welfare system. Comprehensive Paper. Faculty of Social Work, Wilfrid Laurier University. Unpublished paper.

SCHMID, J. \& SYKES, D. 2006. Launching family group conferencing: Maintaining model integrity. OACAS Journal, 49(4):12-15.

SEPTEMBER, R. 2005. Protecting children where it matters most: in their families and their neighbourhoods. Social Work/Maatskaplike Werk, 41(1):27-37.

SEPTEMBER, R. 2006. A review of child protection services in South Africa: State of the art policies in need of implementation. Social Work/Maatskaplike Werk, 42(1):54-67.

SEWPAUL, V. 2001. Models for intervention for children in difficult circumstances in South Africa. Child Welfare, LXXX(5):571-586.

SEWPAUL, V. 2005. A structural social justice approach to family policy: a critique of the draft South African family policy. Social Work/Maatskaplike Werk, 41(4):310-322.

SLOTH-NIELSEN, J.(2005). The rights and responsibilities of parents-guiding principles. Children First, 61(May/June). Available: www.childrenfirst.org.za [Retrieved: 7 August, 2005].

STOCKHOLM UNIVERSITY, DEPARTMENT OF SOCIAL WORK 2003. Country reports 2003. Children and residential care: New strategies for a new millennium. 2nd International Conference, Stockholm, May 12-15, 2003. 
STREAK, J. 2005. Government's social development response to children made vulnerable by HIV/AIDS: Identifying gaps in policy and budgeting. IDASA. Available: www.sarpn.org.za/documents/d0001589/index.php [Retrieved: 12 December, 2005].

SUNDELL, K. \& VINNERLJUNG, B. 2004. Outcomes of family group conferencing in Sweden - a 3-year follow up. Child Abuse and Neglect, 28:267-287.

TAURI, J. 1999. Family group conferencing: The myth of indigenous empowerment in New Zealand. Available: http://www.usask.ca/nativelaw/publications/jah/tauri.html [Retrieved: December 1, 2005.

VANDENBERG, J. \& GREALISH, M. 1996. Individualized services and supports through the Wraparound process: Philosophy and procedures. Journal of Child and Family Studies, 5(1):721.

WALDEGRAVE, C. 2006. Contrasting national jurisdictional and welfare responses to violence to children. Social Policy Journal of New Zealand, 27.

WALDEGRAVE, C., TAMASESE, K., TUHAKA, F. \& CAMPBELL, W. 2003. Just therapy - a journey. Adelaide: Dulwich Centre Publications.

WALDFOGEL, J. 1998. Rethinking the paradigm for child protection. Protecting Children from Abuse and Neglect, 8(1):104-119.

XIAOYUAN, S. \& XIAOMING, W. 2003. Protecting children under financial constraints: "Foster mother villages" in Datong. Journal of Social Policy, 32(4):549-570.

Ms Jeanette Schmid is currently a $3^{\text {rd }}$ year PhD student at the Faculty of Social Work, Wilfrid Laurier University, Kitchener-Waterloo, Canada. 